\title{
PERFORMANCE MEASUREMENT IN VIRTUAL ORGANIZATIONS
}

\author{
Ralf Hieber ${ }^{1}$, Ingo Hartel ${ }^{1}$, Yoichi Kamio ${ }^{2}$ \\ ${ }^{\prime}$ Swiss Federal Institute of Technology Zurich-Center for Enterprise Sciences (ETHZ-BWI), \\ Ralf.Hieber@ethz.ch,Ingo.Hartel@ethz.ch \\ ${ }^{2}$ Toyo Engineering Corporation, kamio@ims.toyo-eng.co.jp
}

\begin{abstract}
The paper gives an overview of a new integral model for performance measurement in virtual organizations. With the focus on the one-of-a-kind production environment, different type of virtual enterprises can be distinguished depending on the deliverables. The paper will focus on the virtual service enterprise, which delivers services such as maintenance, repair, or operation support to customers. By providing generic and aggregated performance indicators an integral and balanced model to measure the performance of a service network as well as virtual service enterprises, which are formed by selected network members, will be provided. A case study has proven the applicability and potential benefits of a collaborative performance measurement in service networks.
\end{abstract}

\section{INTRODUCTION}

For over a decade, there has been a growing interest in the concept of virtual organizations to enlarge own business offerings and solutions, not only in production but also in the field of services, in order to gain additional market shares as well as increase customer satisfaction. Thus, by integrating the core competences of each business partner, companies have realized that the efficiency of their own business success is heavily dependent on the performance of the entire production and service network because of the more and more complex linked value adding processes. Hence, collaborative performance measurement of virtual organizations for determining the network organization success is one of the most critical success factors. Based on the common business strategy and goals, the organization has to evaluate common performance as well as to direct management attention to areas for network improvements.

\section{VIRTUAL ORGANIZATION}

In the search for organization forms for the twenty-first century, the virtual organization concept is beginning to make headway as a dynamic structural pattern. Under this model, organizational units (also called as virtual enterprises) are created, 
restricted to the primary business purposes and thus, this structural simplicity allows maximum economic efficiency. A virtual enterprise can briefly be characterized as a short-term inter-enterprise cooperation where individual enterprises join core competencies in order to establish a value chain configured exactly to meet a specific customer demand. When the customer demand has been fulfilled, the virtual enterprise is decommissioned. With the focus on the one-of-a-kind production different type of virtual enterprises can be distinguished depending on the deliverables (Hartel, 2002). During the use of the one-of-a-kind product (e.g. chemical production facility) the virtual service enterprise offers services such as maintenance, repair, or operation support to the plant owner.

\subsection{The Model of the Virtual Service Organization}

The model of the virtual service organization consists of three main elements - the service network with the network members, the resulting virtual service enterprises (VSE) and the service products. To provide a structural arrangement and to capture the characteristics of these entities the Virtual Enterprise Reference Architecture (VERA) is currently being developed in the IMS GLOBEMEN project. VERA is based upon the GERA modeling framework of GERAM (GERAM, 1999).

Figure 1 shows that the network in its operational phase creates VSEs and a VSE carries out some service product life cycle phases (indicated by the double arrows).

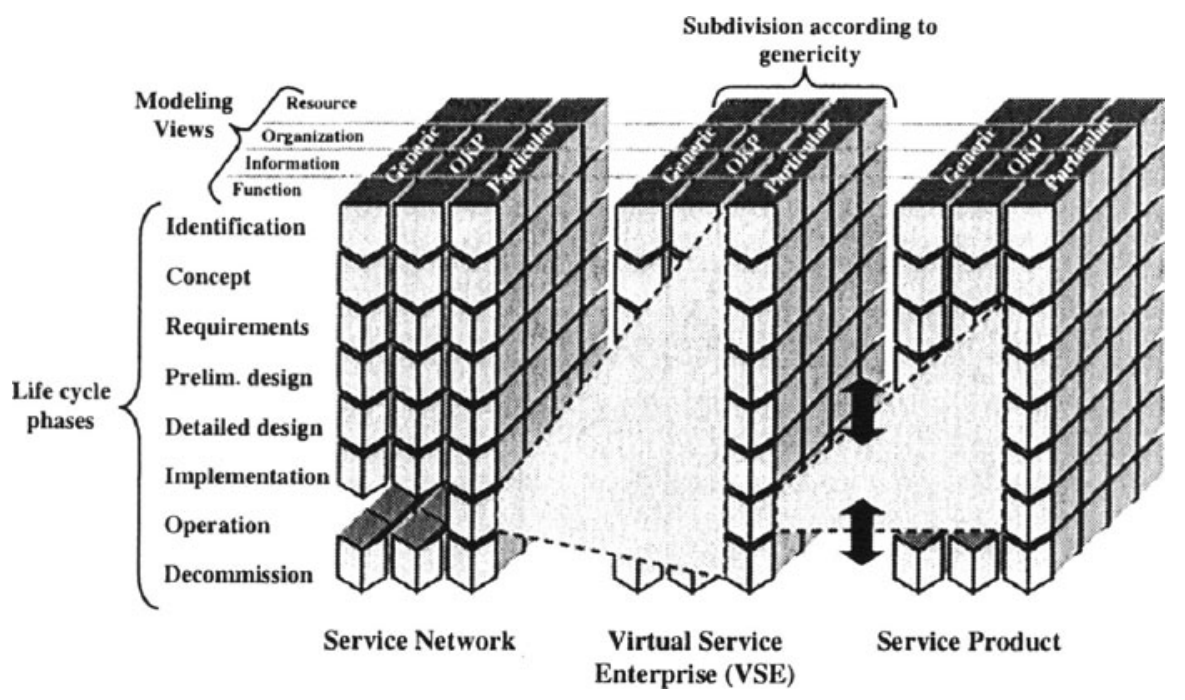

Figure 1 - Virtual Enterprise Reference Architecture (GLOBEMEN, 2000)

The virtual service enterprise is formed of selected network members. Together the network members can fulfill the specified service product. The service product is divided into different tasks. Each network member in the VSE is responsible for performing a part of these tasks in accordance with its competencies and available technical aids and ICT. A service network in the operation phase has an array of service products, which they can offer to the customers. A service product consists of one or several service modules, which through its single or their combined characteristics target distinct customer needs (Hartel, 2002). 


\section{PERFORMANCE MEASUREMENT APPROACHES AND KEY REQUIREMENTS}

The described virtual service organization concept fundamentally changes the nature of organizations, which are nowadays established in this phase of the product life cycle. The service planning and fulfillment is no longer based on own direct ownership and control, but rather on collaboration and coordination across company boundaries as well as interfaces between different departments and different functions, which also finally affects the performance measurement approaches in place. Thus, innovative ways of collaborative performance measurement for virtual service organizations must be developed and new performance dimensions must be taken into consideration that go beyond the traditional dimensions like cost, time and quality. In the following section, the requirements for a new collaborative performance measurement system for a virtual service organization will be derived.

Single network objective-oriented: network members pursue different objectives when participating in a service network. Some members can strive for enhancing and complement core competencies, others for significant know-how increase and further members for developing new markets. As soon as several organizations with different corporate objectives and interests are included, the new challenge is to integrate them in a collaborative way towards a common network objective.

Partnership-oriented: From a collaboration point of view, the partnership orientation in the service network and virtual service enterprise is the most important. The results of numerous studies investigating critical success indicators in the area of supply chain management, have shown put stress on the prerequisite of a win-win partnership for successful network organization. Accordingly, the extent of the partnership that exists between the entities in the network must be evaluated and improved as well.

Balanced-oriented: Many companies have realized the importance of financial as well as non-financial performance measures, but mostly failed to understand them in a balanced framework. According to Kaplan and Norton (Kaplan, 1992), while some managers and researchers have concentrated on financial performance measures, others have concentrated on operational measures. Such an inequality does not lead to metrics that can present a clear and integrated picture of organizational performance.

Model-oriented: On the strength of a systematic approach (e.g. EFQM-model, Malcom Baldrige Award), the performance measurement for service networks and virtual service enterprises should be supported by a generic framework to give guidelines on how to implement and use the recommended performance measures.

Scope-oriented: With respect to the level of detail, the service network and virtual service enterprise performance measurement system should contain any desired eligible elements, thus each network resp. virtual enterprise can tailor its specific scope and objectives after deriving them from overall set of targets and strategies.

Most of the above-described principles for a performance measurement approach are already more or less quite familiar and accepted on a company internal level, however, not from a network perspective as yet, which results by offering joint services towards a common customer (Hieber, 2002). Thus, most of the above principles are nowadays included in recently developed performance measurement 
approaches and, it seems reasonable to include them in a service network context. However, regardless of the performance approach selected on a corporate level, the primary focus must be on supporting a network perspective as a result of a virtual service organization structure.

\section{INTEGRAL MODEL FOR PERFORMANCE MEASUREMENT IN VIRTUAL SERVICE ORGANIZATION}

Most of the current approaches for performance measurement are not designed to strive for and contribute to the global optimum of industrial service network organization including independent one-of-a-kind producers, service companies, suppliers or sub-contractors. Thus, a new model will be introduced, which should overcome these deficiencies and provide a framework for measuring performance in service networks and virtual service enterprises.

\subsection{Generic Performance Target Areas of Virtual Service Organization}

Nowadays, efficient service management has a significant influence on companies performance, especially in the one-of-a-kind industry, in the target areas of quality, costs, and delivery. As a matter of fact, most of the current performance measurement approaches are focusing on these three performance target areas. However, service management in virtual organization enlarges the perspective from a single company's point of view towards a network system's orientation. According to our research, the following three new high-level enabling network and virtual enterprise performance target areas can be identified and are defined as follows:

Service collaboration: The ability to work together by offering joint services and act collaboratively in a win-win partnership to fulfill (final) customer service demand. All service activities should be oriented towards the global optimum of the network.

Service coordination: The ability of service network members to coordinate and communicate efficiently in daily operations. That means that organizations, people, and systems all have access to relevant service information regardless of time, location or company.

Service product configuration: The ability to achieve a high substantial potential of flexibility in (re)configuration of service products between the members in the network by means of practicing and sharing service know-how, capabilities, routines, and skills as well as leveraging ideas and visions.

These performance target areas are dedicated to the overall optimum of a service network and in addition, finally contribute to a very large extent to improvements in inter-company as well as corporate service performance with respect to quality, costs, and delivery.

Thus, these new identified performance target areas of service networks and virtual service enterprises enlarge the current perspective towards a more integral view and hence, will be best reported and measured by common generic network performance indicators. To enable this performance measurement for service networks and virtual service enterprises, the following integral model with the respective assigned performance indicators will be now proposed. 


\subsection{Integral Model for Performance Measurement in Virtual Service Organization}

The integral model is based on the common practices and processes in service management of the participating network entities who are willing to start a joint performance measurement approach. Therefore, the integral model consists of generic as well as aggregated performance indicators of the participating companies in order to (self)assess the performance of the entire service network and virtual service enterprises. However, as figure proposes, a two-phase approach will be recommended.

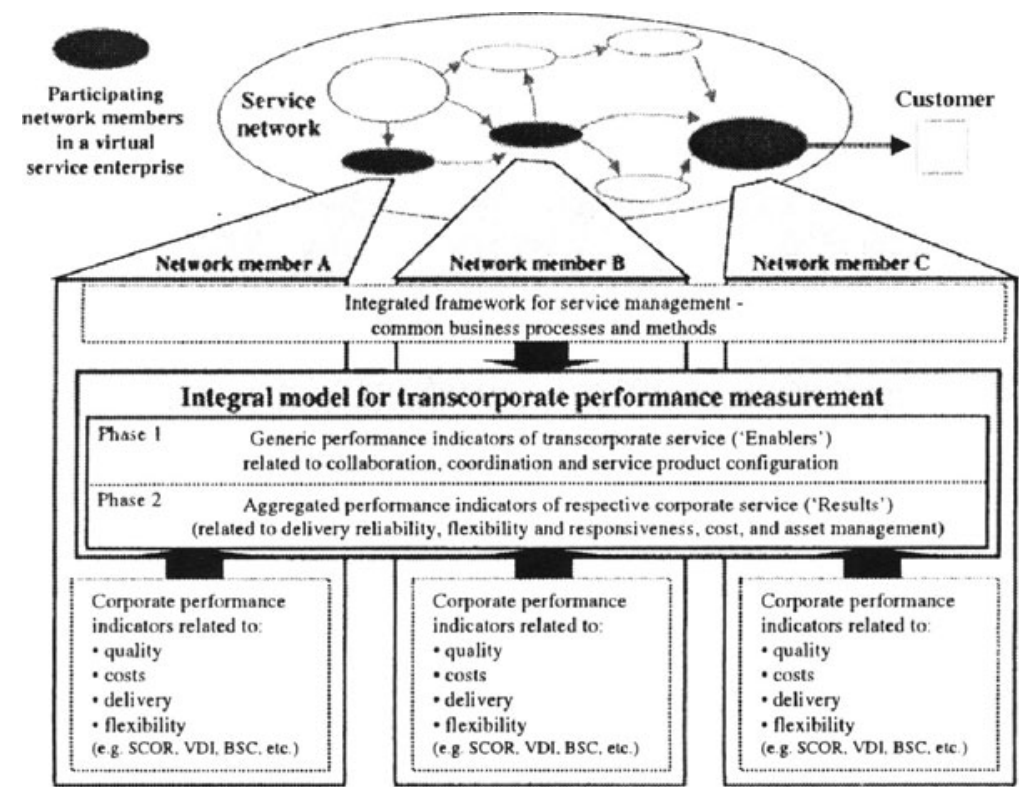

Figure 2 - Integral model for performance measurement

In phase one, generic high-level transcorporate service performance indicators are of main concern (Enablers). These are metrics that mainly address the service collaboration, service coordination, and service product configuration performance target areas of the virtual service organization and record how well the service network and virtual service enterprises are operating. Especially at this early stage of implementing a common performance measurement system, it is very sensitive to already capture and exchange metrics related to internal service cost information or internal service levels. As studies have revealed (Hieber, 2000), network members may be reluctant to share information on service costs or internal service levels, and in addition, the need to release sensitive and confidential information may compound this hesitation. Hence, at the beginning, the performance indicators will first operate on a high-level perspective, rather than on the prevalent result-oriented financial and operational perspective.

In phase two, by building trust and openness and setting up efficient lines of communication during the common operations in the network and virtual enterprises, including monitoring of the generic performance indicators, the integral model can be then enlarged step-by-step with elements of current performance 
measurement approaches with the respective internal corporate service performance target areas of quality, costs, and delivery by aggregating and transforming those on a network and virtual enterprise level (Results).

\subsection{Generic Performance Indicators in Virtual Service Organizations}

To meet these new requirements and to overcome the existing identified shortfalls in service network and virtual service enterprise performance measurement, the next table introduces a new set of high-level generic performance indicators on the intercompany level.

Table 1 - Generic performance indicators: Service 'Enablers'

\begin{tabular}{|c|c|c|}
\hline $\begin{array}{l}\text { Performance } \\
\text { target area }\end{array}$ & Definition & $\begin{array}{l}\text { Generic transcorporate } \\
\text { performance indicator }\end{array}$ \\
\hline $\begin{array}{l}\text { Service } \\
\text { collaboration } \\
\text { efficiency }\end{array}$ & $\begin{array}{l}\text { The ability to work together by } \\
\text { offering joint services and act } \\
\text { collaboratively in a win-win } \\
\text { partnership to fulfill (final) } \\
\text { customer service demand. All } \\
\text { service activities should be } \\
\text { oriented towards the global } \\
\text { optimum of the network. }\end{array}$ & $\begin{array}{l}\text { - Strategic service } \\
\text { alignment } \\
\text { - Service planning } \\
\text { collaboration } \\
\text { - Service execution } \\
\text { collaboration }\end{array}$ \\
\hline $\begin{array}{l}\text { Service } \\
\text { coordination } \\
\text { efficiency }\end{array}$ & $\begin{array}{l}\text { The ability of service network } \\
\text { partners to coordinate and } \\
\text { communicate efficiently in daily } \\
\text { operations. That means that } \\
\text { organizations, people, and } \\
\text { systems all have access to } \\
\text { relevant service information } \\
\text { regardless of time, location or } \\
\text { company. }\end{array}$ & $\begin{array}{l}\text { - Information availability } \\
\text { - Communication } \\
\text { efficiency } \\
\text { - Information and } \\
\text { communication } \\
\text { technology (ICT) } \\
\text { support }\end{array}$ \\
\hline $\begin{array}{l}\text { Service product } \\
\text { configuration } \\
\text { flexibility }\end{array}$ & $\begin{array}{l}\text { The ability to achieve a high } \\
\text { substantial potential of flexibility } \\
\text { in (re)configuration of service } \\
\text { products between the members in } \\
\text { the network by means of } \\
\text { practicing and sharing service } \\
\text { know-how, capabilities, routines, } \\
\text { and skills as well as leveraging } \\
\text { ideas and visions. }\end{array}$ & $\begin{array}{l}\text { - Service product know- } \\
\text { how } \\
\text { - Service product skill } \\
\text { sharing } \\
\text { - Service product } \\
\text { (re)configuration } \\
\text { flexibility }\end{array}$ \\
\hline
\end{tabular}

It is also important to mention, that these performance target areas and assigned performance indicators are the most difficult to record in a quantitative manner. As a consequence, the main interest is not the total score, but more the difference to previous benchmarks. In addition, this proposed set of generic performance indicators should be considered as a starting point for a collaborative performance measurement, rather than a fixed set of predefined indicators. New ones can be added and existing ones can be abandoned, depending on the specific needs of a virtual service organization. 


\section{CASE STUDY}

A Japanese one-of-a-kind producer ("OKP1"), member of the IMS GLOBEMEN project develops and sells large chemical installations. For the manufacture of these installations, it has a large network of suppliers and sub-contractors. Worldwide there are 100 of these installations in operation by customers. In the past, OKP1 developed service components, such as a remote plant monitoring system and a training simulation system, to support after-sales services. However, OKP1 does not have its own team of service technicians. A customer ("C1") operates several installations in Asia and has its own teams for inspection and maintenance. Another large European one-of-a-kind producer ("OKP2"), which is not a direct competitor of OKP1 but works at the same level in the value chain, has a number of its own external service stations in Asia. OKP2 receives support from various service companies if there are capacity bottlenecks or if time is critical. The service network is made up of OKP1 with selected suppliers and sub-contractors, OKP2 with its service stations and service companies in Asia, and $\mathrm{Cl}$ 's service teams. As only OKP1 customers receive the after-sales services, OKP1 takes on the role of hosting provider, who is responsible for network operation and customer contacts.

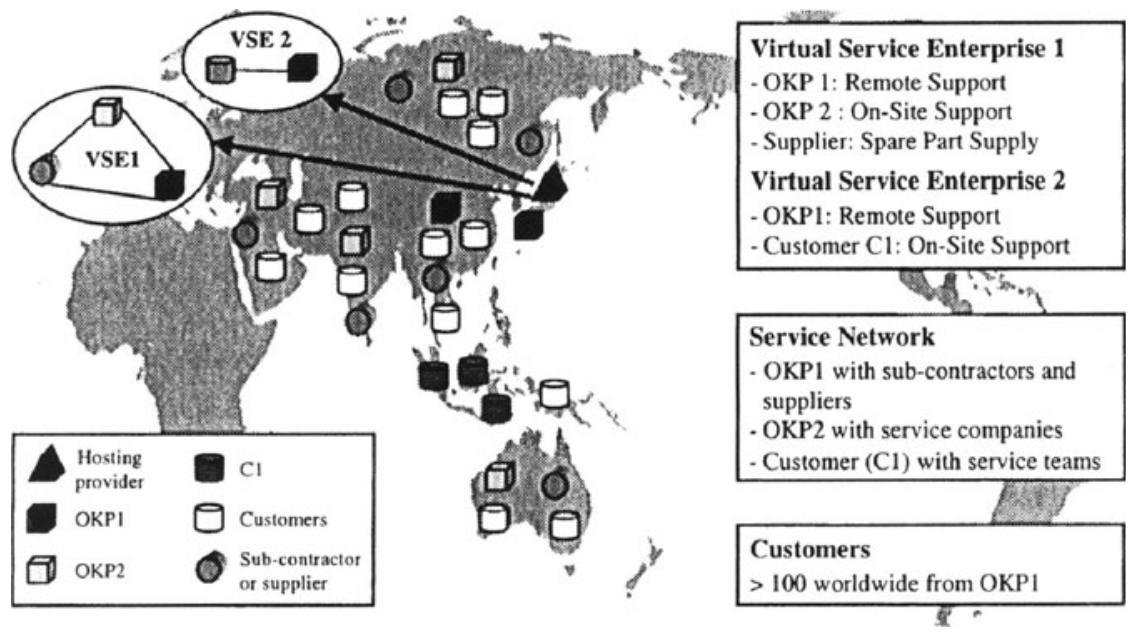

Figure 3 - Structure of the service network

The operating service network is able to provide a wide range of service products, which are configured from available service modules. The service modules are mainly based on the service components, which have already been established at OPK1. For example, if a customer requires maintenance on a reactor and replacement of spare parts of the supply pipes, a virtual service enterprise ("VSE1") could take the following configuration: A service technician from OKP2, who has reactor training, goes on-site to the customer. At the same time, a supplier delivers to the customer the pipes it has manufactured or drawn from inventory. During the repair procedures, the service technician receives additional required information from a developer at OKP1.This form of cooperation described above allows OKP1 to actively offer after-sales services. Through implementing its various service components, OKP1 can gather new experience and data during the operation of the 
installation. In addition, technicians from $\mathrm{Cl}$ will benefit from enlarged experience through service work at other companies. They can apply this experience knowledge within their own company.

By applying the integral model for performance measurement with the assigned service network enabler KPIs, it was possible to detect areas for improvements in a collaborative way. For example, a collaborative service execution in the area of maintenance results in a reduction of the total required service time and cost. Gathered operation data were remotely monitored and analyzed by OKPI using a data acquisition and simulation system. Regarding the determined plant operation condition a maintenance can then better be planed and scheduled. The execution of the maintenance will be done by $\mathrm{C} 1$ or OKP2 supported by remote consulting from OKP1. To further improve the service coordination OKP1 has installed a document management system. This system contains all relevant information from the previous life-cycle phases of the operating plants. All members of an established virtual service enterprise have access via the Internet to the stored data. With the described sharing of skills and the access to relevant service information the overall maintenance efficiency can be enhanced and improvements can be monitored by the newly provided key performance indicators.

\section{CONCLUSION}

The newly proposed generic key performance indicators (Enablers) can be a useful instrument to discern clearly the strengths and areas in which improvements in service management can be made. Moreover, this set of generic performance indicators should be common to the general service performance target areas of almost every service network. Furthermore, these performance indicators can be further broken down in one of the specific performance target areas as applied in the case study in order to fine-tune the specific service network and virtual service enterprise needs.

In general, this set of performance indicators gives a clear picture of what a service network does (network enabler), which will finally lead towards a more result-oriented financial picture of what a service network achieves by setting up virtual service enterprises (network results).

\section{REFERENCES}

1. GERAM. Generalized Enterprise Reference Architecture and Methodology. ISO/DIS15704, IFAC/IFIP Task Force on Architectures for Enterprise Integration, 1999.

2. GLOBEMEN. Global Engineering and Manufacturing in Enterprise Networks. IMS 99004 / IST-199960002, http://globemen.vtt.fi, 2000 - 2003.

3. Hartel I, Burger G, Billinger S, Kamio Y. Virtual organization of after-sales service in the one-of-akind industry. In Luis M. Camarinha-Matos: Collaborative Business Ecosystems and Virtual Enterprises, pp. 405-420, Kluwer Academic Publishers, Boston (USA), 2002, 631 pages.

4. Hieber R. Supply Chain Management - A Collaborative Performance Measurement Approach. vdf Hochschulverlag AG at ETH Zurich, www.vdf.ethz.ch, Zurich (CH), 2002.

5. Hieber R, Windischer A, Alard R, Fischer D. Survey "Successful cooperation in supply chains -trends and practices". Center for Enterprise Sciences (ETHZ-BWI), Zurich (CH), 2000, 24 pages.

6. Kaplan R, Norton D. The Balanced Scorecard - Measures that Drive Performance. In Havard Business Review, January/February 1992, pp. 71-79. 